\title{
Perancangan Sistem Kendali Automatisasi Control Debit Air pada Pengisian Galon Menggunakan Modul Arduino
}

\author{
Sutono $^{1}$, Asri Nursoparisa ${ }^{2}$ \\ Program Studi Teknik Informatika \\ Fakultas Teknik Universitas Suryakancana \\ sutono.unsur@gmail.com ${ }^{1}$,Sastrawinata10@gmail.com ${ }^{2}$
}

\begin{abstract}
Abstrak
Air merupakan zat kehidupan, di mana tidak ada satupun makhluk hidup di bumi ini yang tidak membutuhkan air . Sebagian besar penduduk di Indonesia masih menggunakan air sumur sebagai sumber air bersih untuk memenuhi kebutuhan hidupnya sehari-hari. Dengan bertambahnya aktivitas dan jumlah penduduk, maka jumlah air bersih yang diperlukan manusia akan semakin meningkat. Secara global kuantitas sumber daya tanah dan air relatif tetap, sedangkan kualitasnya makin hari makin menurun.

Pada saat ini terkadang pemilik air galon lupa dalam pengisian air galon karena ketidaktahuan kapan galon yang akan habis. Air galon seringkali tidak terkontrol saat para pemilik galon menggunakan kebutuhan air galon pada keseharian. Karena adanya kesalahan seringnya para pengguna air galon merasa air memenuhi kebutuhan sesuai dengan jumlah orang di dalam rumah maupun didalam kantor padahal kebutuhan air galon tidak cukup untuk memenuhi kebutuhan orang dalam jumlah banyak. Maka dari itu sering sekali ada keterlambatan dalam pengisian air galon. Keterlambatan pengisian galon ini karena tidak terkontrolnya.

Dalam pembuatan sistem ini menggunakan metode pengembangan sistem berdasarkan paradigma Prototype yang terdiri dari Communication, Quick Plan, Modeling Quick Design, Construction Of Prototype, dan Deployment Delivery dan Feedback. Sedangkan untuk metode perancangan sistem menggunakan flowchart. Perangkat yang digunakan merupakan Arduino Mega 2560, Waterflow, Buzzer, RTC Modul DS32321 dan LCD $16 \times 2$ I2C.

Hasil dari penelitian ini diimplementasikan menjadi sebuah alat yang mampun mendeeteksi saat air dalam galon hampir habis. galon yang hampir habis ditandai dengan buzzer yang otomatis berbunyi. Diharapkan dapat meningkatkan ketepatan dalam pengisian air galon dan tidak terjadi keterlambatan dalam pengisian air galon.
\end{abstract}

Kata kunci: Air, Alarm, Prototype, Arduino

\section{PENDAHULUAN}

\subsection{Latar Belakang}

Menurut Fauzi (2011:1) Mikrokontroler adalah sebuah chip yang berfungsi sebagai pengontrol rangkaian elektronik dan umunya dapat menyimpan program didalamnya. Berdasarkan definisi yang dikemukakan diatas dapat disimpulkan bahwa mikrokontroller adalah suatu IC yang didesain atau dibentuk dengan kepadatan yang sangat tinggi,dimana semua bagian yang diperlukan suatu kontroler sudah dikemas dalam satukeping, biasanya terdiri dari CPU (CentralProcessing Unit), RAM (Random AccessMemory), EEPROM/EPROM/PROM/ROM, I/O, Serial \& Parallel, Timer, Interupt Controller dan berfungsisebagai pengontrol rangkaian elektronik serta umunya dapat menyimpan program didalamnya. Dengan metode mikrokontroler ini dapat memudahkan pembuatan alat pendeteksi galon yang hampir habis. Pada era globalisasi saat ini di tengah kemajuan ekonomi dan teknologi yang sangat pesat, untuk memenuhi kebutuhan air minum masyarakat tidak hanya menggunakan air yang dimasak sendiri dari sumber air tanah. Dengan kemasan air dalam galon memudahkan masyarakat untuk memperoleh air.
Namun dengan kemudahan itu ada permasalahan ketika galon yang hampir habis. Terkadang pemilik air galon lupa dalam pengisian air galon karena ketidaktahuan kapan galon yang akan habis. Air galon seringkali tidak terkontrol saat para pemilik galon menggunakan kebutuhan air galon pada keseharian. Karena adanya kesalahan seringnya para pengguna air galon merasa air memenuhi kebutuhan sesuai dengan jumlah orang di dalam rumah maupun didalam kantor padahal kebutuhan air galon tidak cukup untuk memenuhi kebutuhan orang dalam jumlah banyak. Maka dari itu sering sekali ada keterlambatan dalam pengisian air galon. Keterlambatan pengisian galon ini karena tidak terkontrolnya galon yang hampir habis dan tidak ada pemberitahuan galon yang akan habis.

Berdasarkan permasalahan diatas maka dari itu perlu adanya pembuatan alarm untuk mengetahui air galon yang hampir habis. Dengan adanya alat pendeteksi ini pengguna air galon dapat dengan mudah mengetahui galon yang hampir habis karena disediakan alarm pada galon. Alarm pada galon akan berbunyi ketika batas air terdeteksi oleh sensor yang ada pada alat pendeteksi. Meminimalisir tingkat keterlambatan pengisian air galon untuk kebutuhan minum. Maka dari itu penulis memberikan judul untuk penelitian ini dengan judul “ 
Perancangan Sistem Kendali Automatisasi Control Debit Air Pada Pengisian Galon Menggunakan Modul Arduino".

\subsection{Rumusan Masalah}

Berdasarkan latar belakang masalah yang telah diuraikan diatas, maka dapat dirumuskan permasalahan yang timbul yaitu bagaimana membangun sebuah alat Automatisasi Debit Air Galon Menggunakan Arduino.

\subsection{Maksud dan Tujuan}

Maksud dari laporan penelitian ini yaitu pembuatan alat pendeteksi galon untuk mendeteksi kekosongan air galon menggunakan metode mikrokontroler. Adapun tujuan yang ingin dicapai yaitu :

a. Menambahkan komponen alarm untuk galon.

b. Untuk mengetahui air galon hampir habis.

\subsection{Batasan Masalah}

Permasalahan yang akan dibahas yaitu :

a. Alarm hanya dapat berbunyi ketika air galon hampir habis.

b. Alarm akan berhenti bila tombol delay ditekan.

\section{LANDASAN TEORI}

\subsection{Arduino Mega2560}

Arduino Mega 2560 adalah papan pengembangan mikrokontroller yang berbasis Arduino dengan menggunakan chip ATmega2560. Board ini memiliki pin I/O yang cukup banyak, sejumlah 54 buah digital I/O pin (15 pin diantaranya adalah PWM), 16 pin analog input, 4 pin UART (serial port hardware). Arduino Mega 2560 dilengkapi dengan sebuah oscillator $16 \mathrm{Mhz}$, sebuah port USB, power jack DC, ICSP header, dan tombol reset. Board ini sudah sangat lengkap, sudah memiliki segala sesuatu yang dibuthkan untuk sebuah mikrokontroller. Dengan penggunaan yang cukup sederhana, anda tinggal menghubungkan power dari USB ke PC anda atau melalui adaptor AC/DC ke jack DC. (Simanjuntak : 2013, 7)

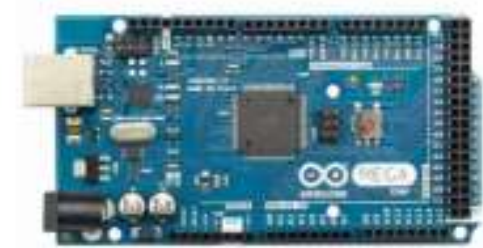

Gambar 1 Arduino Mega 2560

Sifat open source arduino juga banyak memberikan keuntungan tersendiri untuk kita dalam menggunakan board ini, karena dengan sifat open source komponen yang kita pakai tidak hanya tergantung pada satu merek, namun memungkinkan kita bisa memakai semua komponen yang ada dipasaran. Bahasa pemrograman arduino merupakan bahasa $\mathrm{C}$ yang sudah disederhanakan syntax bahasa pemrogramannya sehingga mempermudah kita dalam mempelajari dan mendalami mikrokontroler.

\subsection{Waterflow}

Waterflow merupakan sensor aliran air terbuat dari plastik katup, rotor air, dan sensor aula-efek.
Ketika air mengalir melalui rotor, rotor gulungan, Kecepatannya berubah dengan tingkat yang berbeda aliran. Hall-sensor efek output pulsa yang sesuai Signal.

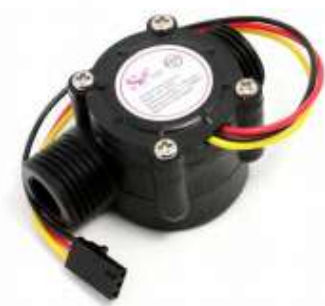

Gambar 2 Waterflow

\subsection{Real Time Clock DS3231}

Real-time clock disingkat RTC adalah jam di komputer yang umumnya berupa sirkuit terpadu yang berfungsi sebagai pemelihara waktu. RTC umumnya memiliki catu daya terpisah dari catu daya komputer (berupa baterai litium) sehingga dapat tetap berfungsi ketika catu daya komputer terputus. Tipe RTC yang digunakan dalam penelitian ini adalah DS3231 yang memiliki spesifikasi sebagai berikut :

a. Real time clock (RTC) meyimpan data-data detik, menit, jam, tanggal, bulan, hari dalam seminggu, dan tahun valid hingga 2100.

b. Komunikasi antarmuka serial two-wire (I2C).

c. Sinyal keluaran gelombang kotak terprogram (programmable squarewave).

d. Ketahanan suhu $0^{\circ} \mathrm{C}$ hingga $70^{\circ} \mathrm{C}$ (komersial) dan $40^{\circ} \mathrm{C}$ hingga $+85^{\circ} \mathrm{C}$ (industrial). 5. Memiliki crystal oscillator internal.

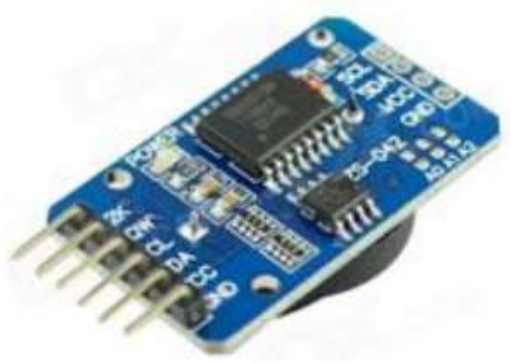

Gambar 3 RTC Module DS3231 1

Penjelasan masing-masing pin RTC DS3231 :

a. $32 \mathrm{~K}$, sebagai keluaran frekuensi $32 \mathrm{KHz}$.

b. SQW, sebagai sinyal kotak ( square wave ) keluaran.

c. SCL, sebagai serial data clock.

d. SDA, sebagai serial data.

e. VCC, sebagai catu daya positif.

f. GND, sebagai catu daya negatif.

\subsection{LCD}

LCD merupakan perangkat elektronik yang dapat digunakan untuk menampilkan angka atau teks. Ada dua jenis utama layar LCD yang dapat menampilkan numerik dan menampilkan teks alfanumerik. Dalam menampilkan numerik ini kristal yang dibentuk menjadi bar, dan dalam menampilkan alfanumerik kristal hanya diatur kedalam pola titik. Setiap kristal memiliki sambungan listrik individu sehingga dapat dikontrol secara independen.

Ketika kristal off' (yakni tidak ada arus yang melalui kristal) cahaya kristal terlihat sama dengan 
bahan latar belakangnya, sehingga kristal tidak dapat terlihat. Namun ketika arus listrik melewati kristal, itu akan merubah bentuk dan menyerap lebih banyak cahaya.

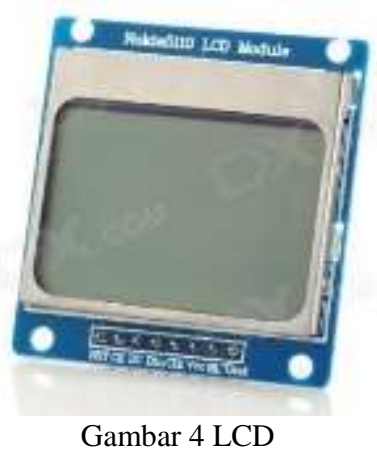

Hal ini membuat kristal terlihat lebih gelap dari penglihatan mata manusia sehingga bentuk titik atau bar dapat dilihat dari perbedaan latar belakang.

\subsection{Buzzer}

Buzzer adalah sebuah komponen elektronika yang berfungsi untuk mengubah getaran listrik menjadi getaran suara. Pada dasarnya prinsip kerja buzzer hampir sama dengan loud speaker, jadi buzzer juga terdiri dari kumparan yang terpasang pada diafragma dan kemudian kumparan tersebut dialiri arus sehingga menjadi elektromagnet, kumparan tadi akan tertarik ke dalam atau keluar, tergantung dari arah arus dan polaritas magnetnya, karena kumparan dipasang pada diafragma maka setiap gerakan kumparan akan menggerakkan 13 diafragma secara bolak-balik sehingga membuat udara bergetar yang akan menghasilkan suara. Buzzer biasa digunakan sebagai indikator bahwa proses telah selesai atau terjadi suatu kesalahan pada sebuah alat (alarm). (Dian. 2012: 20)

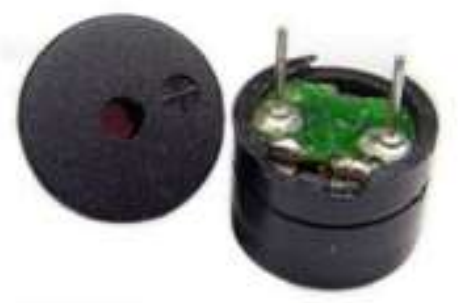

Gambar 5 Buzzer

\subsection{Push Button}

Push button switch (saklar tombol tekan) adalah perangkat / saklar sederhana yang berfungsi untuk menghubungkan atau memutuskan aliran arus listrik dengan sistem kerja tekan unlock (tidak mengunci). Sistem kerja unlock disini berarti saklar akan bekerja sebagai device penghubung atau pemutus aliran arus listrik saat tombol ditekan, dan saat tombol tidak ditekan (dilepas), maka saklar akan kembali pada kondisi normal.

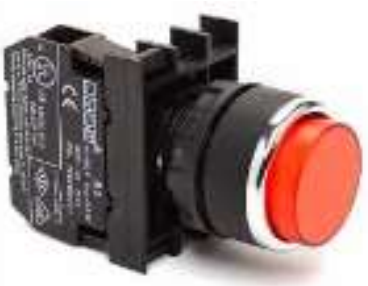

Gambar 6 Push Button

Sebagai device penghubung atau pemutus, push button switch hanya memiliki 2 kondisi, yaitu On dan Off (1 dan 0). Istilah On dan Off ini menjadi sangat penting karena semua perangkat listrik yang memerlukan sumber energi listrik pasti membutuhkan kondisi On dan Off.

Karena sistem kerjanya yang unlock dan langsung berhubungan dengan operator, push button switch menjadi device paling utama yang biasa digunakan untuk memulai dan mengakhiri kerja mesin di industri. Secanggih apapun sebuah mesin bisa dipastikan sistem kerjanya tidak terlepas dari keberadaan sebuah saklar seperti push button switch atau perangkat lain yang sejenis yang bekerja mengatur pengkondisian On dan Off.

\section{7. $\quad$ PCB}

PCB merupakan singkatan dari Printed Circuit Board, yang jika dalam bahasa Indonesia banyak disebut dengan istilah Papan Sirkuit Cetak atau Papan Rangkaian Cetak. PCB ini secara fisik merupakan alat yang digunakan untuk menghubungkan komponen elektronik dalam komputer dengan lapisan jalur konduktornya. Fungsi PCB yaitu :

- Tempat menyusun komponen-komponen elektronik sehingga terpasang lebih rapi dan terorganisir.

- Menghubungkan kaki komponen satu sama lain baik kaki komponen aktif maupun pasif.

- Penggganti kabel untuk menyambung berbagai komponen, sehingga membutuhkan tempat yang lebih efisien.

- Membuat tampilan suatu rangkaian elektronik menjadi lebih rapi dan tertata.

\subsection{Pengujian White Box}

Menurut Pressman (2010, pp. 485), pengujian White-box atau Glass-box adalah metode test-case desain yang menggunakan struktur kontrol desain procedural untuk memperoleh test-case. Dengan menggunakan metode pengujian white-box, perekayasa system dapat memperoleh test-case yang:

- Memberikankan jaminan bahwa semua jalur independent pada suatu modul telah digunakan paling tidak satu kali.

- Menggunakan semua keputusan logis dari sisi true dan false.

- Mengeksekusi semua batas fungsi loops dan batas operasionalnya.

- Menggunakan struktur internal untuk menjamin validitasnya. 


\section{METODE PENELITIAN}

\subsection{Analisis Perancangan}

Analisis perancangan yaitu mengidentifikasi dan mengevaluasi permasalahan dan kebutuhan sehingga mendapatkan usulan untuk perbaikan melalui gambaran, perencanaan dan pembuatan sketsa ke dalam satu kesatuan yang utuh. Dalam analisis perancangan diantaranya terdiri gambaran umum penggunaan perangkat dan perancangan perangkat keras.

\subsection{Perancangan Software Seluruh Perangkat}

Flowchart dibawah ini menjelaskan keseluruhan cara kerja perangkat. Yang diawali oleh waterflow mendeteksi ketersediaan air. Kemudian jika air hampir habis maka buzzer akan berbunyi. Dan terdapat dua push button untuk menghentikan bunyi buzzer dan mereset ulang perangkat.

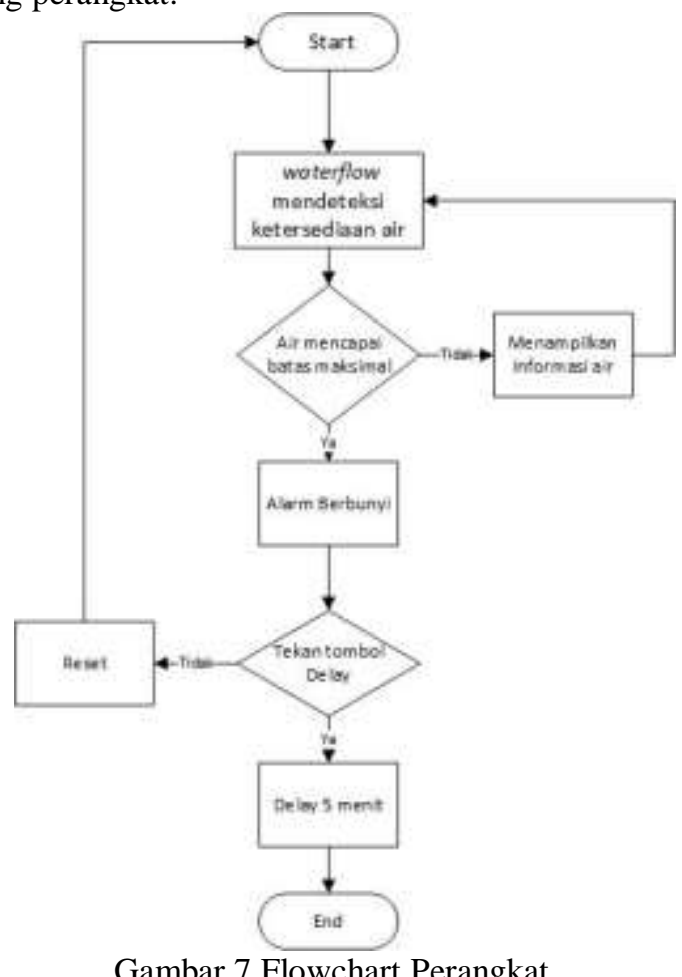

\section{Pseudocode :}

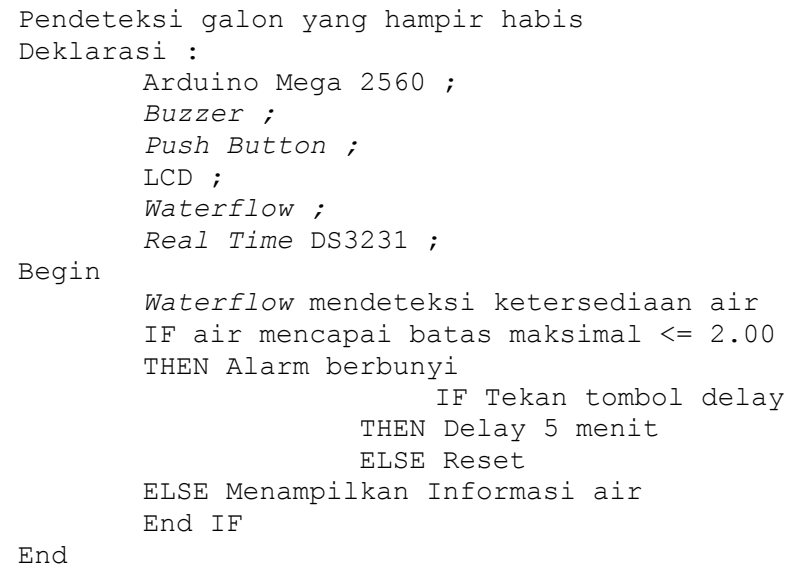

Waterflow memeriksa ketersediaan air. Jika air mencapai batas maksimal air maka alarm akan berbunyi. Jika tombol jeda alarm ditekan maka alarm akan dijeda otomatis selama 5 menit. Jika tombol reset ditekan maka akan muncul settingan awal dari perangkat. Jika ari tidak mencapai batas maksimal atau air masih penuh maka akan menampilkan informasi air yang tersedia.

\subsection{Perancangan Flowchart Waterflow}

Waterflow merupakan sensor aliran air yang terbuat dari plastik katup dan sensor aula-efek. Pada flowchart dibawah fungsi waterflow adalah untuk menghitung debit air yang keluar.

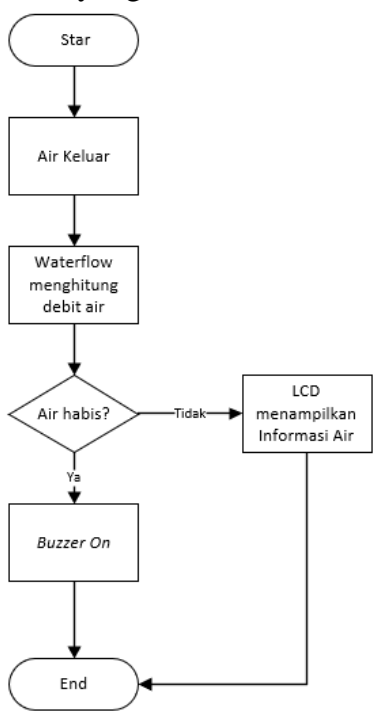

Gambar 8 Flowchart Waterflow

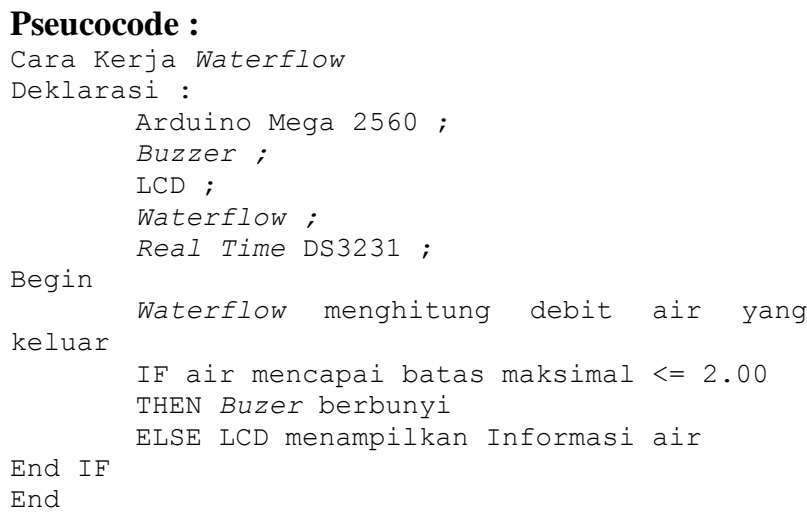

Ketika air keluar melalui Waterflow, kemudian waterflow menghitung debit air yang keluar. Jika air mencapai batas maksimal maka buzzer akan berbunyi jika tidak LCD menampilkan Informasi air.

\subsection{Perancangan Flowchart Push Button}

Push button berfungsi sebagai penghenti buzzer yang nantinya akan berbunyi saat air hampir habis dan berfungsi untuk mereset perangkat pada settingan awal. 


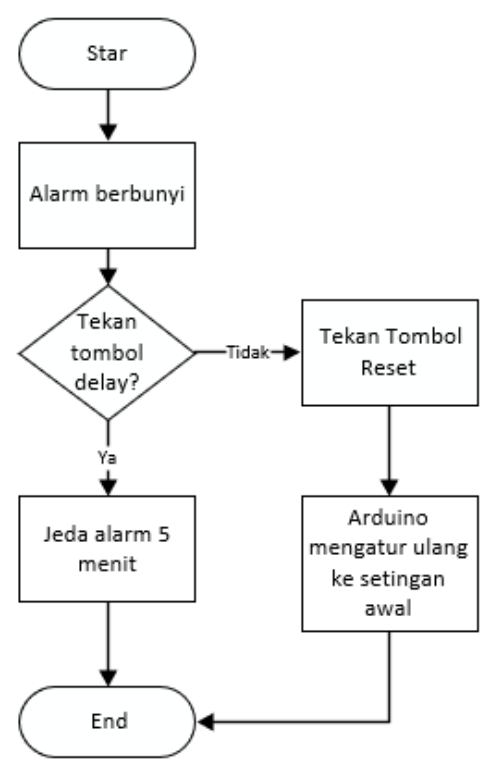

Gambar 9 Flowchart Push Button

\section{Pseudocode :}

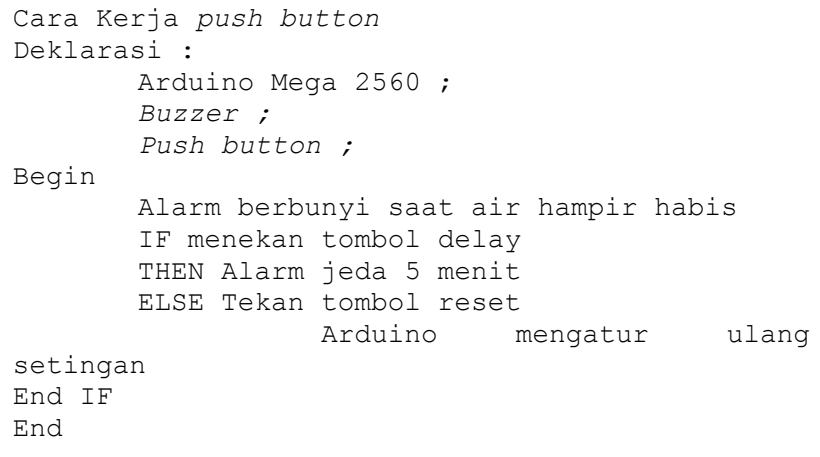

Ketika alarm berbunyi menandai ketersediaan air dalam galon hampir habis. jika menekan tombol delay maka alarm akan terhenti selama 5 menit dan akan berbunyi kembali begitupun seterusnya. Dan jika menekan tombol reset maka arduino akan mengatur ulang settingan kedalam settingan awal ketika ketersediaan air masih maksimum.

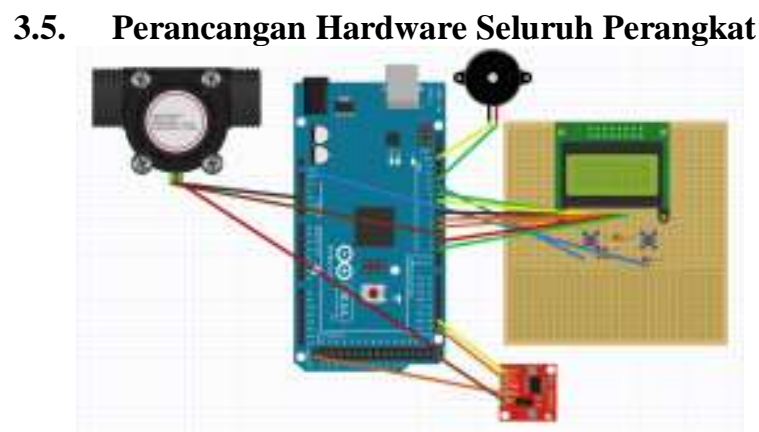

Gambar 10 Perancangan Perangkat

Perancangan ini merupakan perancangan keseluruhan dari Arduino Mega R3 dengan modulmodul yang saling berkaitan. PCB merupakan penghubung antara lcd dan button yang di gabungkan oleh kabel jumper agar terhubung dengan arduino mega r3. Waterflow merupakan komponen penghitung air dalam galon. DS3231 RTC modul sebagai pengatur jeda atau delay ketika galon tidak diisi langsung. Buzzer berbunyi ketika waterflow telah mencapai batas maksimal air. Button berfungsi sebagai reset dan delay.

\subsection{Perancangan Waterflow}

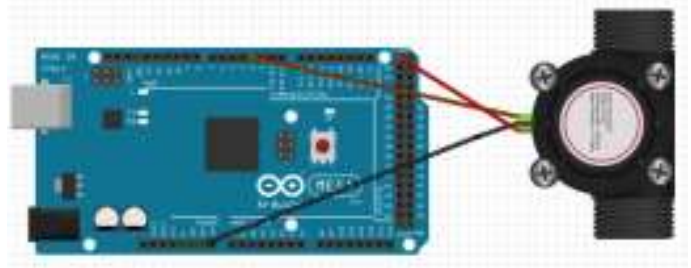

Gambar 11 Perancangan Waterflow

Perancangan waterflow merupakan rangkaian waterflow yang dihubungkan oleh kabel jumper agar terhubung dengan arduino mega r3. Waterflow berfungsi sebagai alat penghitung debit air yang ada di dalam galon, dimana batar maksimal debit air galon sudah di tentukan.

Tabel 1 Pin Waterflow

\begin{tabular}{|c|c|c|}
\hline No & Waterflow & Arduino \\
\hline 1 & Kabel Kuning & Pin 3 \\
\hline 2 & Kabel Hitam & GND \\
\hline 3 & Kabel Merah & $5 \mathrm{~V}$ \\
\hline
\end{tabular}

Pada rangkaian ini, waterflow mempunyai 3 kabel. Tiga kabel ini langsung dihubungkan dengan Arduino Mega 2560 dengan menggunakan kabel jumper. Pada kabel warna kuning dihubungkan pada pin 3 yang terdapat pada arduino mega 2560. Untuk kabel warna hitam dihubungkan pada pin GND kemudian untuk kabel warna merah dihubungkan pada pin $5 \mathrm{~V}$.

\subsection{Perancangan DS3231}

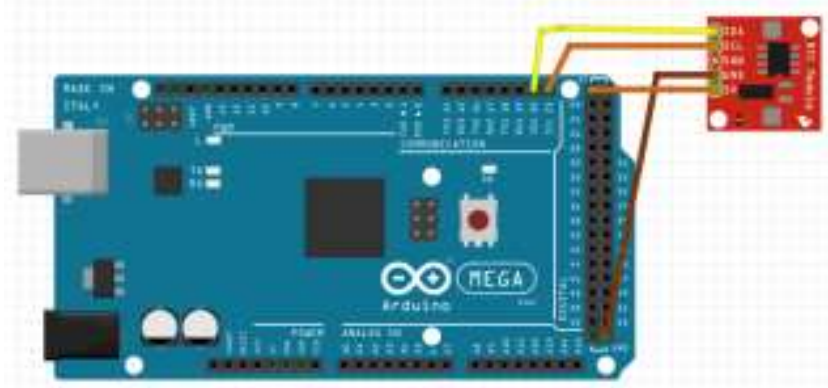

Gambar 12 Perancangan RTC DS3231

Rangkaian DS3231 RTC Modul sebagai pengatur waktu jeda pada buzzer yang di atur selama 30 menit dan buzzer akan berbunyi kembali ketika 30 menit kemudian. DS3231 RTC Modul dihubungkan menggunakan kabel jumper agar terhubung dengan arduino mega $\mathrm{r} 3$.

Tabel 2 Pin RTC Module

\begin{tabular}{|c|c|c|}
\hline No & DS3231 & Arduino Mega \\
\hline 1 & GND & GND \\
\hline 2 & VCC & 5V \\
\hline 3 & SDA & SDA20 \\
\hline 4 & SCL & SCL21 \\
\hline
\end{tabular}

Pada rangkaian ini, DS3231 memiliki 5 pin yaitu SDA, SCL, GND, VCC dan ROW. Yang dihubungkan pada arduino mega 2560 hanya 4 pin. Pada pin SDA dihubungkan pada pin arduino SDA 21. Pin SCL dihubungkan pada arduino pin SCL20. Pin GND dihubungkan pada pin digital arduino yaitu pin GND. 
Sedangkan pin VCC dihubungkan pada pin digital arduino $5 \mathrm{~V}$.

\subsection{Perancangan Buzzer}
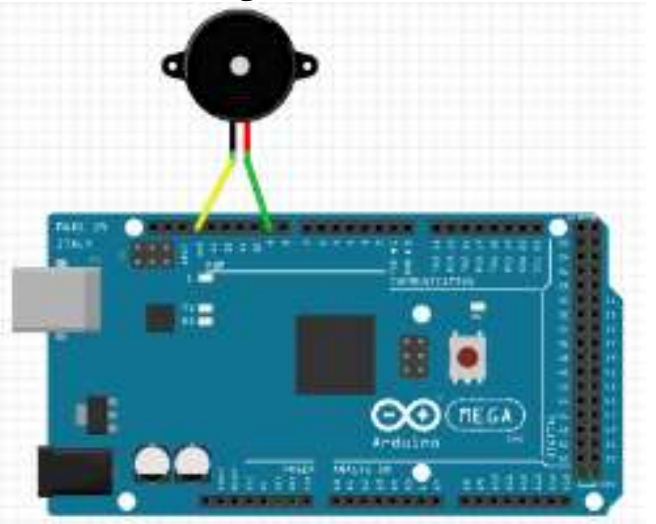

Gambar 13 Perancangan Buzzer

Rancangan buzzer di hubungkan dengan arduino mega r3 menggunakan kabel jumper. Buzzer akan berbunyi sebagai sinyal ketika isi galon mengurang menandakan air galon agar di isi segera yang dihitung menggukan waterflow.

Tabel 3 Pin Buzzer

\begin{tabular}{|c|c|c|}
\hline No & Buzzer & Arduino Mega \\
\hline 1 & GND & GND \\
\hline 2 & Pin Digital & Pin 9 \\
\hline \multicolumn{3}{|c|}{ Pada rangkaian ini, buzzer dihubungkan }
\end{tabular}
langsung dengan kabel jumper ke arduino mega 2560. Pada kabel berwarna hitam dihubungkan pada pin GND arduino sedangkan kabel merah dihubungkan pada pin 9 arduino mega 2560.

\subsection{Perancangan Button dan LCD}

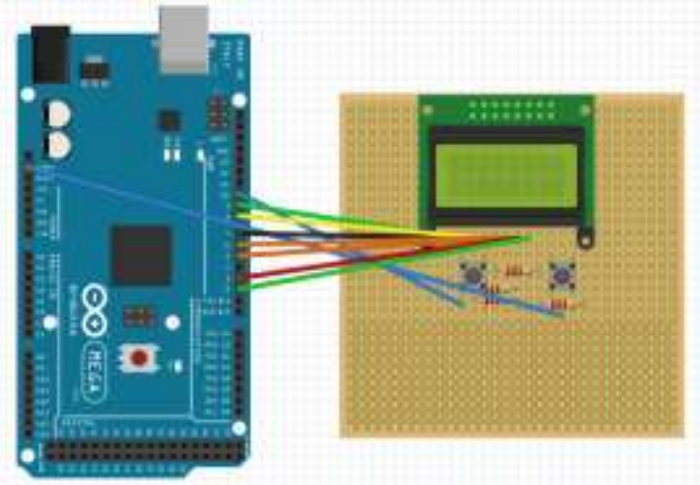

Gambar 14 Perancangan LCD dan Button

Perancangan LCD dan Button menjadi satu rangkaian. LCD dan Button ditempelkan dengan cara disolder ke papan stripboard dialiri listrik menggunakan resistor. Pada LCD akan menampilkan informasi ketersediaan air sedangkan button berfungsi untuk mereset dan menjeda alarm yang berbunyi.

Tabel 4 Pin Button

\begin{tabular}{|c|c|c|}
\hline No & Button & Arduino Mega \\
\hline 1 & Reset & Pin Reset \\
\hline 2 & VCC & Pin 5v \\
\hline
\end{tabular}

\begin{tabular}{|c|c|c|}
\hline \multicolumn{3}{|c|}{ Tabel 5 Pin LCD } \\
\hline No & LCD & Arduino Mega \\
\hline 1 & Kabel kuning & Pin 3 \\
\hline 2 & Kabel Orange & Pin 4 \\
\hline 3 & Kabel Merah & Pin 5 \\
\hline
\end{tabular}

\begin{tabular}{|c|c|c|}
\hline 4 & Kabel Coklat & Pin 6 \\
\hline 5 & Kabel Hijau & Pin 7 \\
\hline
\end{tabular}

\subsection{Perancangan Antarmuka}

Perancangan antarmuka merupakan tampilan implementasi dari sistem yang dibangun. Tampilan yang ditampilkan oleh LCD. Terdapat tampilan ketersediaan Air Galon.

\section{A. Antarmuka ketersediaan Air Galon}

Ketersediaan Air Galon

Awal 2,5 L

Sisa $0,5 \mathrm{~L}$

Gambar 15 Antarmuka Ketersediaan Air

Tampilan diatas merupakan tampilan yang akan muncul pada layar LCD. Tampilan awal saat alat dinyalakan.

\section{B. Antarmuka ketersediaan Air Galon Hampir}

Habis

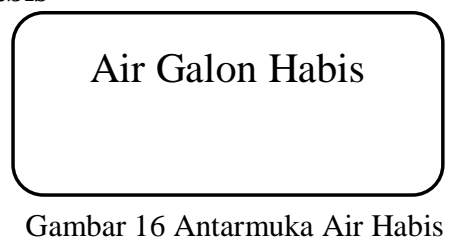

Tampilan diatas merupakan tampilan yang akan muncul pada layar LCD. Tampilan saat Waterflow mendeteksi air yang hampir habis.

\section{HASIL DAN PEMBAHASAN}

\subsection{Pengujian Flowchart seluruh perangkat}

Pendeteksi galon yang hampir habis Deklarasi :

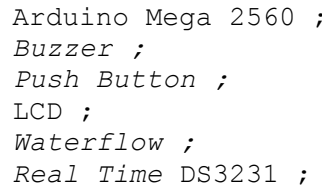

Waterflow mendeteksi ketersediaan air IF air mencapai batas maksimal $<=2.00$ THEN Alarm berbunyi IF Tekan tombol delay THEN Delay 5 menit ELSE Reset

ELSE Menampilkan Informasi air 
Sutono $^{1}$, Asri Nursoparisa ${ }^{2}$, Perancangan Sistem Kendali Automatisasi Control Debit Air pada Pengisian

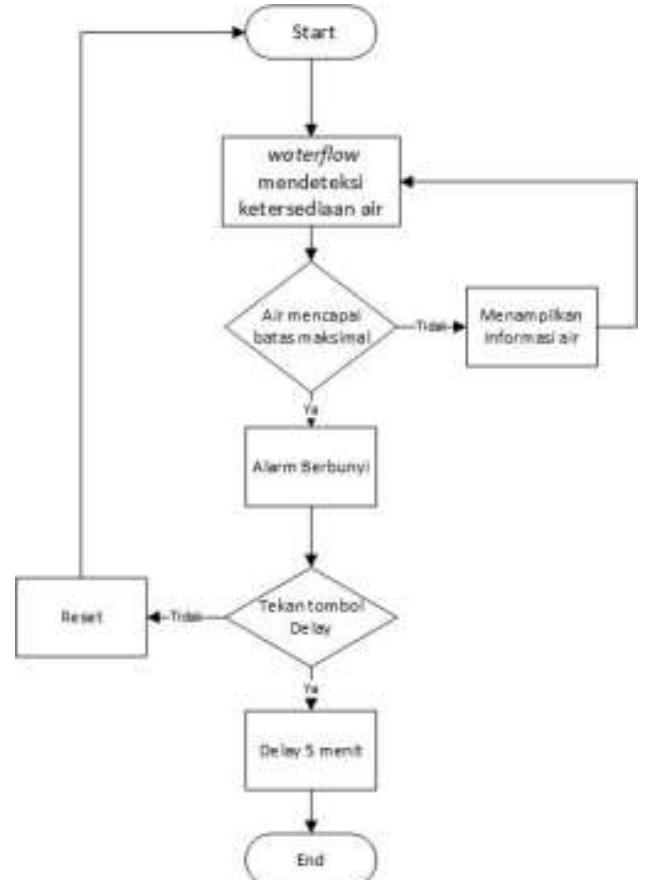

Galon Menggunakan Modul Arduino

Gambar 17 Flowchart Perangkat

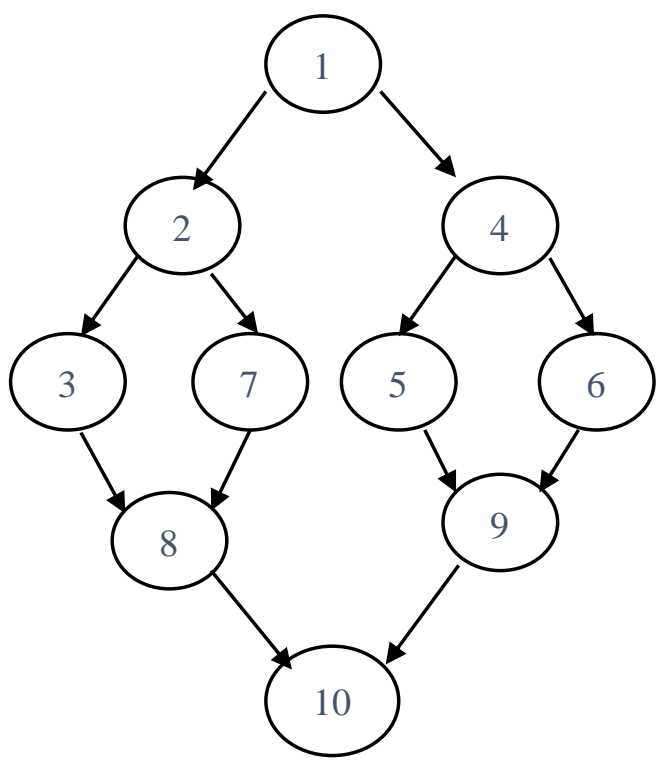

Gambar 18 Pengujian White Box Keseluruhan Perangkat

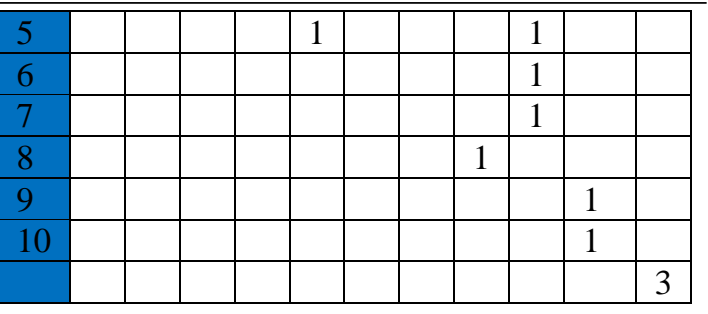

\subsection{Pengujian Flowchart Waterflow}

Cara Kerja Waterflow

Deklarasi :

Arduino Mega 2560 ;

Buzzer ;

$\mathrm{LCD}$;

Waterflow ;

Real Time DS3231; Begin

Waterflow menghitung debit air yang

keluar

IF air mencapai batas maksimal $<=2.00$

THEN Buzer berbunyi

ELSE LCD menampilkan Informasi air

End IF

End

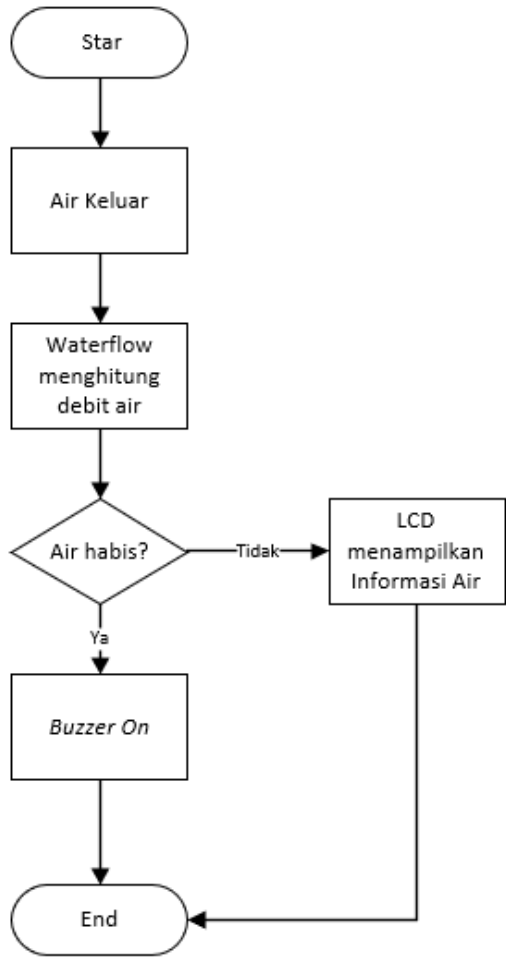

a. Region 4

b. Hasil cyclomatic complexity

$\mathrm{V}(\mathrm{G})=\mathrm{E}-\mathrm{N}+2$

$\mathrm{V}(\mathrm{G})=12-10+2$

$\mathrm{V}(\mathrm{G})=4$

c. Path
1. $=1,2,3,8,10$
2. $=1,2,7,8,10$
3. $=1,4,5,9,10$
4. $=1,4,6,9,10$

d. Graph Matrix

\begin{tabular}{|l|l|l|l|l|l|l|l|l|l|l|l|}
\hline & 1 & 2 & 3 & 4 & 5 & 6 & 7 & 8 & 9 & 10 & \\
\hline 1 & & 1 & & 1 & & & & & & & 1 \\
\hline 2 & & & 1 & & & & 1 & & & & 1 \\
\hline 3 & & & & & & & 1 & & & & 0 \\
\hline 4 & & & & & & 1 & & & & & 1 \\
\hline
\end{tabular}




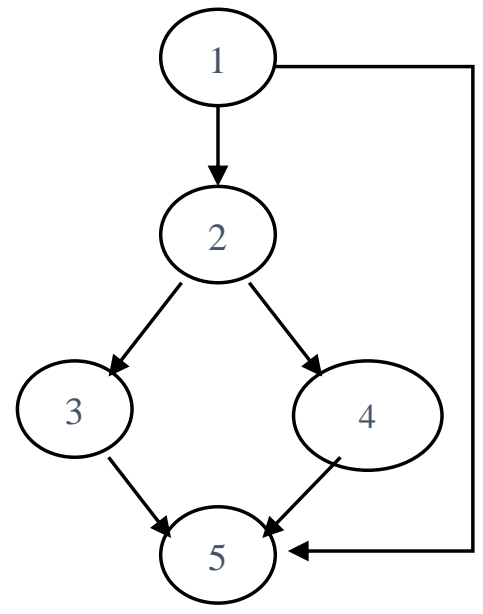

Gambar 20 Pengujian White Box Waterflow
a. Region 3
$\mathrm{V}(\mathrm{G})=\mathrm{E}-\mathrm{N}+2$
$\mathrm{V}(\mathrm{G})=6-6+2$
$\mathrm{V}(\mathrm{G})=2$

b. Hasil cyclomatic complexity

\section{c. Path}

1. $=1,2,3,5,6$

2. $=1,2,4,5,6$

3. $=1,2,5,6$

d. Graph Matrix

\begin{tabular}{|l|l|l|l|l|l|l|l|}
\hline & 1 & 2 & 3 & 4 & 5 & 6 & \\
\hline 1 & & 1 & & & 1 & & 1 \\
\hline 2 & & & 1 & 1 & & & 1 \\
\hline 3 & & & & & 1 & & 0 \\
\hline 4 & & & & & 1 & 1 & 0 \\
\hline 5 & & & & & & 1 & 0 \\
\hline & & & & & & & 2 \\
\hline
\end{tabular}

\subsection{Pengujian Flowchart Push Button}

Cara Kerja push button

Deklarasi :

Arduino Mega 2560 ;

Buzzer ;

Push button ;

Begin

Alarm berbunyi saat air hampir habis

IF menekan tombol delay

THEN Alarm jeda 5 menit

ELSE Tekan tombol reset

Arduino mengatur ulang setingan

End IF

End.
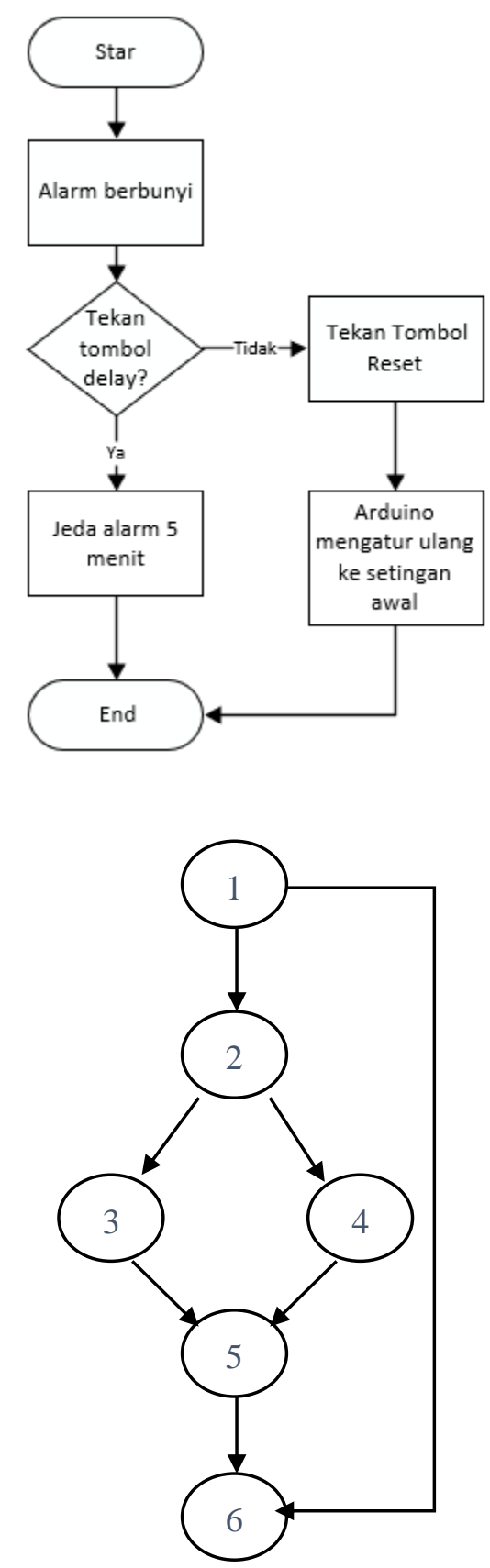

Gambar 21 Pengujian White Box Push Buttton

a. Region 3

b. Hasil cyclomatic complexity

$\mathrm{V}(\mathrm{G})=\mathrm{E}-\mathrm{N}+2$

$\mathrm{V}(\mathrm{G})=6-6+2$

$\mathrm{V}(\mathrm{G})=2$

c. Path
1. $=1,2,3,5,6$
2. $=1,2,4,5,6$
3. $=1,2,5,6$

d. Graph Matrix

\begin{tabular}{|l|l|l|l|l|l|l|l|}
\hline & 1 & 2 & 3 & 4 & 5 & 6 & \\
\hline 1 & & 1 & & 1 & & 1 & 1 \\
\hline 2 & & & 1 & 1 & 1 & & 1 \\
\hline 3 & & & & & & 1 & 0 \\
\hline 4 & & & & & & 1 & 0 \\
\hline 5 & & & & & & 1 & 0 \\
\hline & & & & & & & 2 \\
\hline
\end{tabular}




\subsection{Pengujian Input dan Output}

\begin{tabular}{|l|l|l|}
\hline \multicolumn{3}{|c}{ Tabel 6 Pengujian } \\
\hline No & Alokasi & Fungsi \\
\hline 1. & SCL & IN1 DS3231 \\
\hline 2. & GND & 1N2 DS3231 \\
\hline 3. & Pin 9 & Buzzer \\
\hline 4. & Pin Reset & Reset \\
\hline 5. & Pin 4 & IN1 LCD \\
\hline 6. & Pin 5 & IN2 LCD \\
\hline 7. & Pin 6 & IN3 LCD \\
\hline 8. & Pin7 & IN4 LCD \\
\hline 9. & Pin3 & Waterflow \\
\hline 10. & GND & IN2 DS3231 \\
\hline
\end{tabular}

\subsection{Pengujian Catu Daya}

Rangkaian catu daya akan memberikan sumber tegangan untuk rangkaian yang berada di dalam rancangan. Tegangan yang keluar dari catu daya sebesar 12 VDC untuk supply arduino . Sedangkan untuk supply rangkain lainnya diambil dari pin Power pada arduino yaitu sebesar 5 VDC. Untuk mengetahui apakah tegangan sudah benar masuk ke masing-masing rangkaian maka dilakukan pengukuran menggunakan multimeter. Pada tahap pengujian dilakukan pada pengujian rangkaian dan tegangan yang dihasilkan dari catu daya. Hasil pengujian pada tahap pertama didapatkan hasil yang sudah sesui dengan tegangan yang diminta yaitu tegangan $5 \mathrm{~V}$ dan tegangan $12 \mathrm{~V}$ dan rangkaian secara keseluruhan bekerja dengan baik.

Tabel 7 Hasil Pengukuran

\begin{tabular}{|l|l|l|}
\hline No & \multicolumn{1}{|c|}{ Rangkaian } & Hasil Pengukuran \\
\hline 1. & Arduino & 12 Volt \\
\hline 2. & Rangkaian Push Button & 5 Volt \\
\hline 3. & Rangkaian LCD & 5 Volt \\
\hline
\end{tabular}

\section{IMPLEMENTASI PERANGKAT}

Implementasi sistem adalah tahap penerapan sistem yang dilakukan setelah perancangan sistem selesai dibuat dan tentunya perancangan tersebut sesuai dengan hasil analisa, maka implementas sistem dibuat dengan mengacu kepada perancangan awal sehingga hasilnya sesuai dengan kebutuhan.

a. Implementasi Arduino

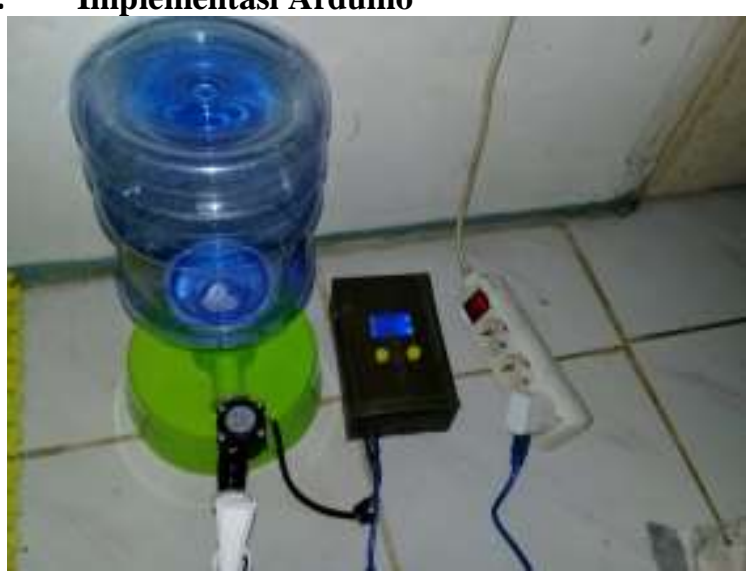

Gambar 21 Implementasi Arduino Seluruh Perangkat

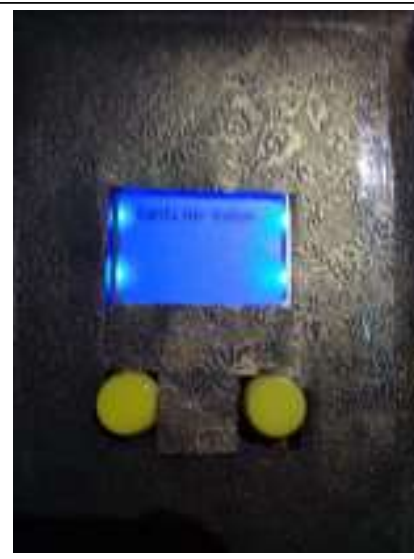

Gambar 22 Tampilan LCD saat air galon Kosong

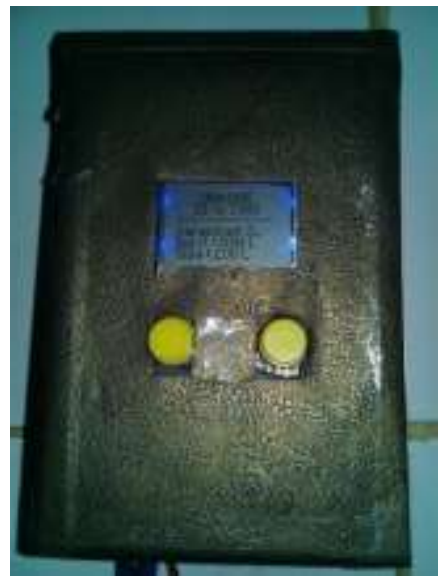

Gambar 23 Tampilan LCD

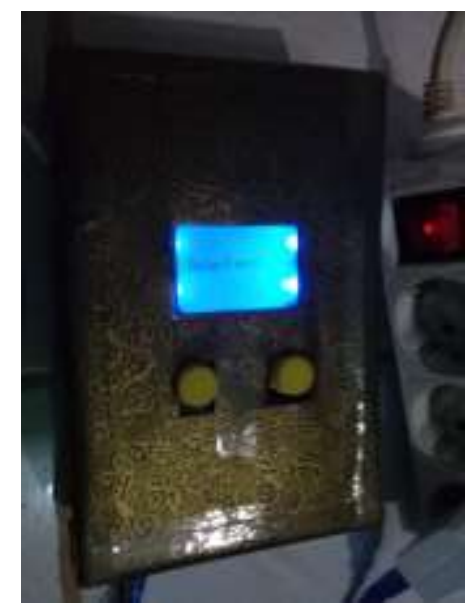

Gambar 24 Tampilan LCD saat Informasi dELAY

\section{KESIMPULAN}

Berdasarkan hasil penelitian, perancangan dan implementasi yang dilakukan dapat diambil beberapa kesimpulan, diantaranya :

- Pendeteksi galon yang kosong telah selesai dibuat dan dapat berjalan sesuai dengan perancangan namun masih terdapat kendala yaitu dalam pemberitahuan waktu delay tidak terdapat waktu mundur.

- Pengguna air galin tidak khawatir untuk mengkonsumsi air galon di rumah karena pengisian air galon dapat terkontrol dengan adanya pendeteksi kekosongan air galon dan adanya buzzer yang berbunyi. 


\section{SARAN}

Untuk meningkatkan kinerja perangkat, maka penulis mengajukan beberapa saran kepada pihak yang akan mengembangkan sebagai pengembangan selanjutnya, antara lain :

- Pengembangan ditambahkan modul tombol untuk menghentikan buzzer saat pengisian air galon.

- Pengembangan perangkat lunak untuk tetap mengontrol mengontrol air galon dimana pun dan kapan pun.

\section{DAFTAR PUSTAKA}

[1] Arduino. 2015. Accessed June 22, 2017. https://www.Arduino.cc/en/Reference/HomePage. Diambil kembali dari www.Arduino.cc.

[2] Djuanda, F. 2011. TOBUKU.COM. January 8. Accessed June 22, 2017. http://tobuku.com/index.php/2011/01/08/ pengenalan-Arduino/.

[3] Djuanda, Feri. 2011. Pengenalan Arduino. Jakarta: Elexmedia.

[4] Juhana, Drs. M. Suratman dan Ir Ohan. 2001. Servis dan Reparasi Mobil. Pustaka Grafika.

[5] Parsimin. 2013. MEMBANGUN SISTEM INFORMASI BERBASIS WEBSITE PADA SMP NEGERI 4 PURWANEGARA. Yogyakarta: AMIKOM.

[6] Pressman, Roger S. 2010. Software Engineering. 7. Newyork: McGraw Hill.

[7] Santoso, Hari. 2015. Panduan Praktis Arduino Untuk Pemula V.1. Jakarta: Elang Sakti.

[8] Sari, Siska Komala. 2015. "Jurnal." Analisis dan Pemodelan Proses Bisnis Prosedur Pelaksanaan Proyek Akhir Sebagai Alat Bantu Identifikasi Kebutuhan Sistem 144-146.

[9] Wrihatnolo, Randy R. 2008. Monitoring, evaluasi, dan pengendalian : Konsep dan Pembahasan. Surabaya.

[10] Yakub. 2012. Pengantar Sistem Informasi. Yogyakarta: Graha Ilmu.

[11] Yulianto, Ardhian Agung, dkk. 2009:2.

[12] Djuandi, F., 2011. www.tobuku.com. [Online] Available at: tobuku.com/docs/ArduinoPengenalan.pdf

[13] Electronics, I., 2013. www.innovativeelectronics.com. [Online] Available at: http://www.innovativeelectronics.com [Diakses 4 Mei 2017].

[14] Fritzing, F.-o.-F. f., 2016. fritzing. [Online] Available at: http://fritzing.org [Diakses 293 2017]. 